\title{
ESTUDIOS DE DERECHO PRIVADO. II JORNADAS NACIONALES DE PROFESORAS DE DERECHO PRIVADO *
}

\author{
SUSAN TURNER SAELZER **
}

Tal como destaca la presentación del libro hecha por la profesora Leonor ETCHEBERRY, "estamos frente a un gran volumen construido únicamente por mujeres". Se trata de las conferencias y ponencias llevadas a cabo durante las Segundas Jornadas Nacionales de Derecho Privado que se realizaron en agosto de 2019 en la Universidad de la Frontera.

Este libro compilatorio de 33 trabajos, coordinado por las organizadoras de las mismas Jornadas, profesoras María Elisa Morales y Pamela Mendoza, tiene la virtud de identificar los temas en los que se concentra la discusión dentro de las distintas subespecialidades ius privatistas. En este sentido, el lector que busca enterarse del estado actual de las controversias doctrinarias y jurisprudenciales del área, tanto nacionales como comparadas, podrá encontrar una panorámica completa en estas páginas. A su vez, el lector que desee revisar quiénes se desempeñan como profesoras de derecho privado en un gran número de universidades chilenas, específicamente, en 20, tendrá a su disposición un cuadro exhaustivo. En definitiva, entonces, el libro que se reseña constituye un aporte a la dogmática chilena del derecho privado tanto desde el punto de vista de la amplitud de los temas abarcados como así también, desde el punto de vista de la amplitud de las autoras: académicas

\footnotetext{
* Morales, María Elisa; Mendoza, Pamela (coord), Estudios de Derecho Privado. II Jornadas Nacionales De Profesoras De Derecho Privado, DER Ediciones, Santiago, 2020.

** Licenciada en Ciencias Sociales y Jurídicas, Universidad de Chile. Doctora en Derecho, Universidad de Göttingen, Alemania. Profesora de Derecho Civil, Universidad Austral de Chile, Valdivia, Chile. Correo electrónico: sturner@uach.cl. ORCID: https://orcid.org/0000-0003-2476-4294

Trabajo recibido el 11 de marzo de 2021, y aprobado para su publicación el 1 de mayo de 2021.
} 
de amplia trayectoria se intercalan con otras que están iniciando su carrera universitaria, académicas de universidades tradicionales lo hacen con otras de universidades privadas. En fin, académicas de regiones se suceden con académicas de la capital.

Si a ello le agregamos una cuidadosa edición, pulcra en su estilo y estética, resulta que la publicación del libro es una buena noticia para todos los que cultivan el derecho privado, ya sea como abogados, investigadores o jueces.

Los trabajos se agruparon según su contenido. En la sección de Derecho privado general y Bienes, encontramos ponencias sobre la noción de sujeto en el derecho privado (¿cómo se relacionan las concepciones tradicionales del sujeto como agente moral con las nuevas provenientes de las neurociencias?); sobre la noción de patrimonio (¿qué significa el patrimonio cultural y qué problemas específicos acarrea?), sobre la noción de derecho común (¿cómo ha aplicado la jurisprudencia nacional el concepto de derecho común para adaptar las instituciones a los cambios sociales?) y sobre el significado de "valor" y "vicio" en la normativa de nulidad (¿qué sentido tienen dichas palabras en la regulación del Código Civil sobre nulidad? En relación a los Bienes, encontramos trabajos sobre acción reivindicatoria (¿qué significa "mejor derecho" en la acción publiciana, según las distintas fuentes del CC?) y sobre la propiedad (¿constituye el sistema de regularización de la propiedad del DL 2695 una vulneración del sistema general de inscripción del dominio?).

La sección relativa al Derecho de las personas y de familia, aborda temáticas clásicas y emergentes. Entre las primeras encontramos trabajos sobre la procedencia de la renuncia de derechos de familia (¿puede renunciarse al derecho a exigir una compensación económica en caso de divorcio?); sobre la posesión notoria del estado de hijo (¿existen razones para considerar a la posesión notoria una acción de filiación?). Entre las segundas, los escritos aluden a instituciones clásicas, pero ahora analizadas a la luz de los derechos fundamentales. Así, se cuestiona la noción civil de capacidad jurídica (¿se ajusta la capacidad civil y la declaración de interdicción a los estándares de la Convención de los Derechos de Personas con Discapacidad?); se analiza la incidencia de la discapacidad intelectual en el cuidado personal de los hijos (¿admite la autonomía de las personas con discapacidad intelectual una restricción a sus derechos parentales?); se caracteriza la gestación por sustitución y su incidencia sobre la maternidad (¿cómo debe regularse esta figura para proteger los derechos del hijo?) y el 
trasplante de útero (¿cómo se vincula este y la maternidad subrogada?); la medida de acogimiento familiar (¿respeta este sistema el derecho del niño a vivir en familia?) y la violencia de género en el contexto de las relaciones de pareja (¿cómo ha reaccionado el estado chileno ante la violencia de género?).

A la sección referida a la responsabilidad civil debe agregarse la conferencia de cierre de la profesora SAN MARTín alusiva a la función que cumpliría dicha responsabilidad (¿es posible identificar, además de sus funciones clásicas, una función social o asistencial en el régimen de responsabilidad civil?); un análisis de la responsabilidad extracontractual a la luz del género (¿el estándar de conducta objetivo comprende a las mujeres, sufren las mujeres daños distintos a los hombres?); un estudio del trabajo doméstico como ítem indemnizable (¿puede resarcirse la pérdida de la capacidad para desarrollarlo y cómo tendría que valorarse?); un trabajo sobre la responsabilidad por el daño causado por un miembro indeterminado de un grupo determinado (¿cómo se ha resuelto esa hipótesis en el derecho comparado?); sobre la delimitación entre responsabilidad por culpa de la organización y por el hecho de su dependiente (¿existe esta distinción en el caso Karadima?); y sobre los modelos de responsabilidad de los padres por los hechos de sus hijos menores (¿qué alternativas existen para regular esta responsabilidad?).

A la sección de Obligaciones y Contratos pertenece la conferencia de la profesora VÁsQuEZ sobre modernización del derecho de contratos y su influencia en el ámbito chileno (¿cómo ha impactado en Chile la nueva perspectiva sobre la vinculación contractual y sobre los remedios por incumplimiento?); además de un trabajo acerca de la vigencia de los tradicionalmente denominados cuasicontratos (¿qué camino debiera seguir el legislador al regularlos?); sobre interpretación contractual (¿cómo debe interpretarse una cláusula de ajuste de contrato por cambio de ley?; sobre compraventa (¿qué opciones tiene el comprador en el caso de ventas sucesivas frente al incumplimiento doloso del vendedor?); sobre la excepción de incumplimiento previsible (¿cómo se vincula la excepción regulada en nuestro CC con la desarrollada por la Convención de Viena sobre Compraventa Internacional?); y sobre los contratos de servicios (¿qué aspectos de este tipo de contratos desarrollados en el derecho comparado deberían contemplarse en una futura regulación nacional?).

La última sección del libro agrupa trabajos relativos al Derecho comercial, Propiedad intelectual y Derecho del consumo. Se analiza desde el punto de vista del Derecho comercial el giro de las nuevas aplicaciones 
de transporte urbano (¿qué tipo de actividad desarrolla Uber según el Código de Comercio y cómo la regulan los distintos proyectos de ley sobre la materia?). En cuanto a la Propiedad intelectual, se cuestiona la autoría frente a la inteligencia artificial ( $¿$ deben protegerse las obras generadas por inteligencia artificial a través del concepto de autoría?) y las particularidades de las marcas en el área farmacéutica (¿cómo las aborda la llamada Ley de Fármacos II?). En cuanto al Derecho del consumo, las ponencias abordan temáticas más generales, como la que se refiere a la ubicación dogmática que debiera darse a esta disciplina del Derecho (¿qué lugar le corresponde en la clásica dicotomía Derecho privado vs. Derecho público?); o como aquella que relaciona el derecho del consumo con el derecho probatorio (¿cómo opera en la práctica la carga dinámica de la prueba en los procesos de protección al consumidor?). Otros trabajos analizan las particularidades del consumidor como sujeto del contrato: el desequilibrio respecto del otro contratante (¿qué tutela ofrece la Ley sobre Protección de los Derechos de los Consumidores frente al desequilibrio contractual comparado con el CC?); y la tutela preventiva con que cuenta el consumidor frente a un producto defectuoso (¿en qué consisten los deberes preventivos y cuáles son?). 